\title{
Short-term and long-term repeatability of the morning blood pressure in older patients with isolated systolic hypertension
}

\author{
Barbara Wizner ${ }^{\mathrm{a}, \mathrm{b}}$, Dirk G. Dechering ${ }^{\mathrm{c}}$, Lutgarde Thijs ${ }^{\mathrm{a}}$, Neil Atkins ${ }^{\mathrm{d}}$, \\ Robert Fagard ${ }^{a}$, Eoin O'Brien ${ }^{\mathrm{e}}$, Peter W. de Leeuw ${ }^{\mathrm{f}}$, Gianfranco Parati ${ }^{\mathrm{g}}$, \\ Paolo Palatini ${ }^{h}$, Denis Clement', Tomasz Grodzicki ${ }^{i}$, Kazuomi Kario ${ }^{j}$ \\ and Jan A. Staessen ${ }^{\mathrm{a}}$
}

Objective Using 24-h ambulatory blood pressure monitoring, we studied the repeatability of the morning blood pressure in older ( $\geq 60$ years) patients with isolated systolic hypertension.

Methods The sleep-through morning surge was the morning blood pressure minus the lowest nighttime blood pressure. The preawake morning surge was the morning blood pressure minus the preawake blood pressure. In addition, we determined the cusum plot height of blood pressure from 04:00 to 10:00 h from a plot of cumulative sums.

Results In 173 patients with repeat recordings within 33 days (median), the short-term repeatability coefficients, expressed as percentages of maximal variation, ranged from 35 to $41 \%$ for the daytime and nighttime blood pressures and from 50 to $56 \%$ for the night-to-day blood pressure ratios. Short-term repeatability ranged from 52 to $75 \%$ for the sleep-through and the preawake morning surge, and from 51 to $62 \%$ for the cusum plot height. In 219 patients with repeat recordings within 10 months (median), the corresponding long-term estimates ranged from 45 to $64 \%$, from 69 to $71 \%$, from 76 to $83 \%$, and from 50 to $78 \%$, respectively. In categorical analyses of the short-term repeatability of the sleep-through morning surge and the preawake morning surge, using the 75th percentile as arbitrary cut-off, surging status changed in $\mathbf{2 8 . 0}$ and $\mathbf{2 6 . 8 \%}$ of patients ( $\kappa$-statistic $\leq \mathbf{0 . 3 3}$ ). In the long-term interval, these proportions were 32.0 and $32.0 \%$, respectively ( $\kappa$-statistic $\leq 0.20$ ). The $\kappa$-statistic threshold for moderate reproducibility is $\mathbf{0 . 4}$.

\section{Introduction}

Blood pressure (BP) shows marked diurnal variation, reaching the highest level in the morning and then decreasing through the day to a trough level during the first hours of sleep at night. The morning surge is the rise in BP on awakening and might be a predictor of cardiovascular complications [1-5]. Japanese hypertensive patients with mean age of 72 years had a higher risk of multiple brain infarcts and stroke if the morning surge in systolic BP was above the 90th percentile [2], or if the
Conclusion The morning surge of blood pressure is poorly reproducible, irrespective of whether it is analysed as continuous or categorical variable. J Hypertens 26:13281335 (c) 2008 Wolters Kluwer Health | Lippincott Williams \& Wilkins.

Journal of Hypertension 2008, 26:1328-1335

Keywords: ambulatory blood pressure monitoring, clinical trials, cumulative sums, morning surge, reproducibility

Abbreviations: BP, Blood Pressure; $\mathrm{Cl}$, Confidence Interval; $\mathrm{CPH}$, Cusum Plot Height; MS, Morning Surge; RC, Repeatability Coefficient; SD, Standard Deviation

aStudies Coordinating Centre, Division of Hypertension and Cardiovascular Rehabilitation, Department of Cardiovascular Diseases, University of Leuven, Leuven, Belgium, 'Department of Internal Medicine and Gerontology, Jagiellonian University Medical College, Krakow, Poland, 'Department of General Internal Medicine, University Medical Centre St Radboud, Radboud University, Nijmegen, the Netherlands, ${ }^{\text {B }}$ lood Pressure Unit and ADAPT Centre Beaumont Hospital, Dublin, ${ }^{e}$ Conway Institute of Biomolecular and Biomedical Research, University College Dublin, Belfield, Dublin, Ireland, 'Department of Internal Medicine, University of Maastricht, Maastricht, the Netherlands,

${ }^{9}$ Department of Clinical Medicine and Prevention, University of Milano-Bicocca and Department of Cardiology, San Luca Hospital, Instituto Auxologico Italiano, Milan, 'First Medical Clinic, University of Padua, Padua, Italy, 'Department of Cardiology, University of Ghent, Ghent, Belgium and 'Division of Cardiovascular Medicine, Department of Medicine, Jichi Medical University School of Medicine, Tochigi, Japan

Correspondence to Jan A. Staessen, MD, PhD, FESC, FAHA, Studies Coordinating Centre, Division of Hypertension and Cardiovascular Rehabilitation, Department of Cardiovascular Diseases, University of Leuven, Campus Gasthuisberg, Herestraat 49, Box 702, B-3000 Leuven, Belgium Tel: +32 1634 7104; fax: +32 1634 7106;

e-mail: jan.staessen@med.kuleuven.be

Received 16 January 2008 Revised 10 March 2008 Accepted 17 March 2008 difference of systolic BP between morning and evening was above the top quartile $(>20 \mathrm{mmHg})[6]$.

In the Ohasama Study, a morning surge above the top quintile systolic $(\geq 25 \mathrm{mmHg})$ predicted intracerebral haemorrhage [7]. The use of arbitrary thresholds to define the morning surge in BP limits the generalizability of previous studies. As highlighted by other researchers [8-13], the repeatability of the classification of subjects according to their $\mathrm{BP}$ is another important issue to be 
considered. In this article, we assessed the short-term and long-term repeatability of the morning surge, using continuous definitions [2,7] and previously published thresholds $[3,6]$. For this, we analysed the database of the substudy on ambulatory BP monitoring of the Systolic Hypertension in Europe (Syst-Eur) trial [14].

\section{Methods}

\section{Study design and selection of patients}

The Ethics Committee of the Faculty of Medicine at the University of Leuven as well as the Institutional Review Boards of all participating centres approved the protocol. Eligible patients were 60 years or older. On conventional measurement, they had a sitting systolic $\mathrm{BP}$ ranging from 160 to $219 \mathrm{mmHg}$ with a diastolic BP of less than $95 \mathrm{mmHg}$. Standing systolic BP had to be $140 \mathrm{mmHg}$ or more. These entry criteria rested on the mean of six BP readings obtained during the single-blind placebo run-in period (two readings in each position at three visits one month apart). Eligible patients were stratified by sex and the presence vs. absence of cardiovascular complications and were randomized to double-blind treatment with placebo or active medication.

Of 198 Syst-Eur centres, 46 opted to enrol their patients in the substudy on ambulatory BP monitoring. To be included in the present analysis, patients had to have had their ambulatory BP measured twice during the run-in period (short-term repeatability), or had to have had one baseline recording and one follow-up measurement of their ambulatory BP on double-blind placebo within 2 years of randomization (long-term repeatability). Of 837 randomized patients, 173 and 219 qualified for the analysis of short-term and long-term repeatability, respectively. The total number of patients statistically analysed was 320 .

Of 173 patients with duplicate ambulatory BP recording during the run-in period, 72 also underwent a third recording after randomization to double-blind placebo treatment. In 62 of these patients, the quality of the recordings was sufficient to compute the morning surge on all three occasions.

\section{Ambulatory blood pressure monitoring}

We programmed properly validated portable monitors to obtain BP readings at intervals no longer than $30 \mathrm{~min}$ [14]. Editing criteria encoded in the monitor were disabled or set at limits as wide as possible. The cuff was secured to the nondominant arm. If on conventional sphygmomanometry the difference in systolic BP between both arms was $10 \mathrm{mmHg}$ or more, the arm with highest readings was chosen. We used larger cuffs with a $33 \mathrm{~cm} \times 15 \mathrm{~cm}$ bladder if arm circumference exceeded $31 \mathrm{~cm}$.

We excluded the first hour of each recording from analysis (white-coat window) $[15,16]$. If the ambulatory recordings were longer than 1 day, we only analysed the first $24 \mathrm{~h}$. We defined daytime and nighttime as the intervals ranging from 10:00 to 20:00 $\mathrm{h}$ and from midnight to $06: 00 \mathrm{~h}$, respectively. We weighted the within-subject means of the daytime and nighttime BPs for the interval between consecutive readings [14].

We limited the categorical analyses to systolic BP, because above 50 years it is a better predictor of cardiovascular complications than diastolic BP $[17,18]$.

\section{Morning surge of blood pressure}

For analysis of the morning surge in BP, we determined the awake and asleep periods from the patients' diary cards. We defined the sleep-through morning surge (Fig. 1) as the difference between the morning pressure (the average $\mathrm{BP}$ during the $2 \mathrm{~h}$ after waking up) and the lowest nighttime BP (the average of the lowest pressure and the two readings immediately preceding and following the lowest value) [2]. We also studied the preawake morning surge (Fig. 1), as the difference between the morning BP (the average BP during the $2 \mathrm{~h}$ after waking up) and the preawake BP (the average BP during the $2 \mathrm{~h}$ before waking up) [2,7]. In categorical analyses, we applied the 75 th percentile as the arbitrary threshold of exaggerated sleep-through $(40 \mathrm{mmHg})$ and preawake $(25 \mathrm{mmHg})$ morning surges.

In addition, we used cumulative sums (cusum) [19] for a continuous assessment of the $\mathrm{BP}$ changes in the morning from 04:00 to 10:00 h. We computed the cusum at time ' $t$ ' and the cusum plot height according to the formula:

$\operatorname{Cusum}_{(t)}=\sum_{i=2}^{t}\left(\frac{\mathrm{BP}_{i}+\mathrm{BP}_{i-1}}{2}-\right.$ mean BP $) d_{i}$

Cusum plot height $=\left|\max \left(\operatorname{cusum}_{t}\right)-\min \left(\operatorname{cusum}_{t}\right)\right|$

$$
\times(t=2, \ldots, n)
$$

where

mean $\mathrm{BP}=\frac{\sum_{i=2}^{n}\left(\mathrm{BP}_{i}+\mathrm{BP}_{i-1} / 2\right) d_{i}}{\sum_{i=2}^{n} d_{i}}$

and $n$ is the number of $\mathrm{BP}$ measurements between 04:00 and $10: 00 \mathrm{~h}, \mathrm{BP}_{i}$ is the $i$ th $\mathrm{BP}$ measurement between 04:00 and 10:00 h, $d_{i}$ is the time interval in hours between $\left(\mathrm{BP}_{i}\right.$ and $\left.\mathrm{BP}_{i-1}\right)$.

To be eligible for the cumulative sums analysis, the ambulatory recordings had to include at least one reading per hour during the time interval from 04:00 to 10:00 h. If $\mathrm{BP}$ was not measured at 04:00 h, an estimated value was generated by mean interpolation from the measurements immediately before and after 04:00 h. Similarly, if BP 


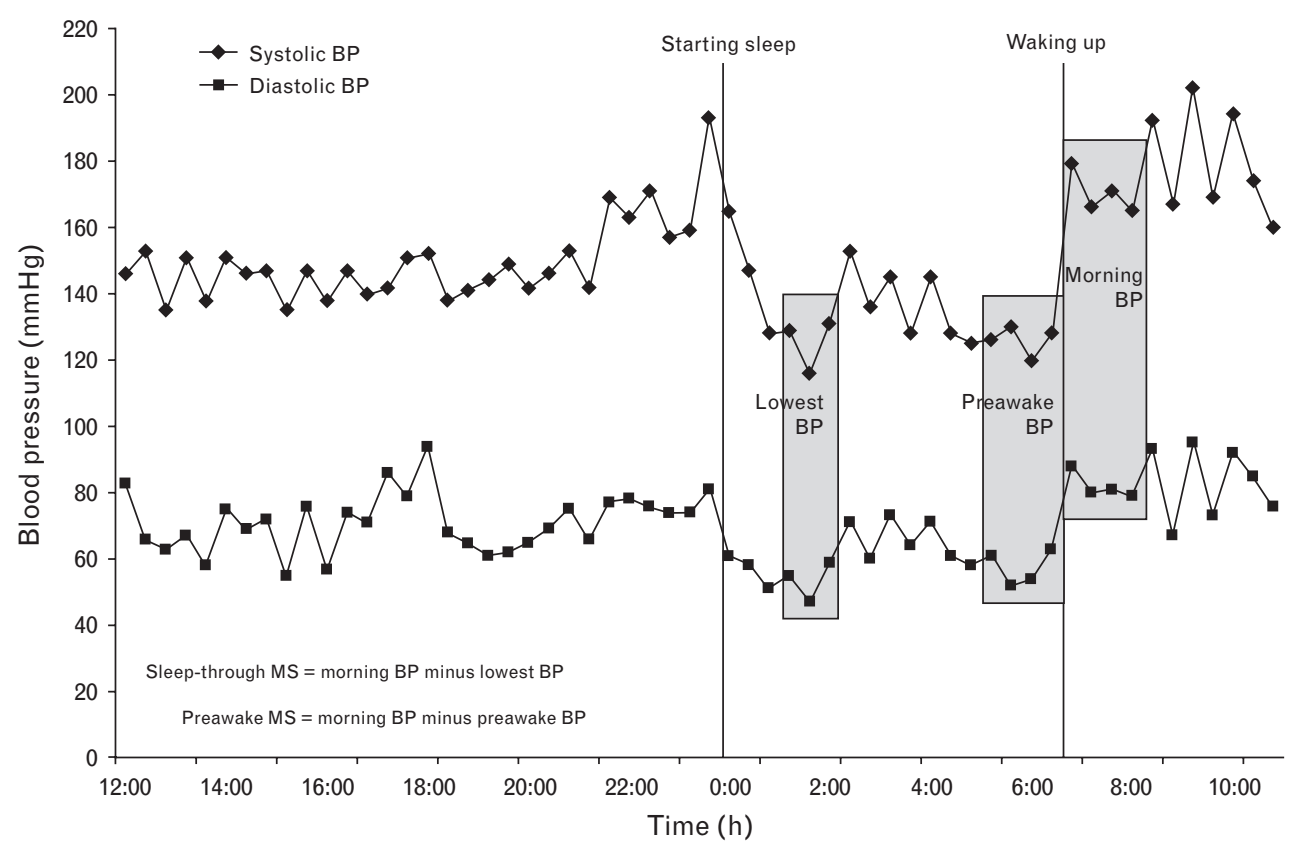

Derivation of the sleep-through and preawake morning surge from the 24-h ambulatory blood pressure recording of a representative patient. BP, blood pressure; MS, morning surge.

was not measured at 10:00 h, an estimated value was generated from the measurements immediately before and after 10:00 h. The cusum plot height was the difference between the maximum and the minimum of the cusum curve (Fig. 2). The cusum plot height measures both the extent and steepness of the BP increase in the morning hours.

\section{Statistical methods}

For database management and statistical analysis, we used SAS software, version 9.1.3 (SAS Institute Inc, Cary, North Carolina, USA). We compared means and proportions by Student's $t$-test for paired and unpaired observations, as appropriate, and the $\chi^{2}$-statistic, respectively. We assessed the agreement between paired ambulatory recordings by Bland and Altman's method [20,21]. We used the repeatability coefficient for the evaluation of the short-term and long-term repeatability [22]. It was twice the standard deviation of the within-subject differences between repeat recordings (repeat minus first). We expressed the repeatability coefficient as a percentage of the mean of the repeat measurements, as well as the percentage of close to maximal variation (four times the standard deviation of the average of the repeat measurements). In categorical analyses, we applied McNemar's test and we computed the $\kappa$-statistic [23] as a measurement of agreement. Finally, we used simple regression analysis to correlate differences between repeated measures of the changes in the morning pressure with difference in the time of awakening between consecutive recordings.

\section{Results}

\section{Baseline characteristics}

Of the 320 patients, 195 (60.9\%) were female and 86 (26.9\%) had a history of previous cardiovascular complications. Mean age $( \pm \mathrm{SD})$ was $70.5 \pm 6.0$ years (range, $60-$ 88 years). Body mass index averaged $26.7 \pm 4.3 \mathrm{~kg} / \mathrm{m}^{2}$ in women and $26.0 \pm 3.5 \mathrm{~kg} / \mathrm{m}^{2}$ in men. The prevalence of smoking was $5.1 \%$ in women and $19.2 \%$ in men $(P<0.001)$. The number of patients drinking alcohol amounted to 27.7 and $64.8 \%(P<0.001)$, respectively. There were no statistical differences in the characteristics of the patients included in the analysis of short-term and long-term repeatability. Figure 3 shows the distributions of the sleep-through and preawake morning surge, the cusum plot height and night-to-day ratio in 320 patients whose $\mathrm{BP}$ was recorded during the placebo run-in period.

\section{Short-term repeatability}

In the 173 patients available for the study of the shortterm repeatability, the median time-interval between the duplicate measurements was 33 days (interquartile range, 28-46 days; range, 2-127 days). The technique of ambulatory $\mathrm{BP}$ recording was consistently oscillometric in 137 patients $(79.2 \%)$ and consistently auscultatory in 20 patients $(11.6 \%)$.

During the run-in period, there were no significant differences between the repeat recordings in the mean values for the daytime and nighttime BPs, the night-today $\mathrm{BP}$ ratios, the sleep-through and preawake morning 

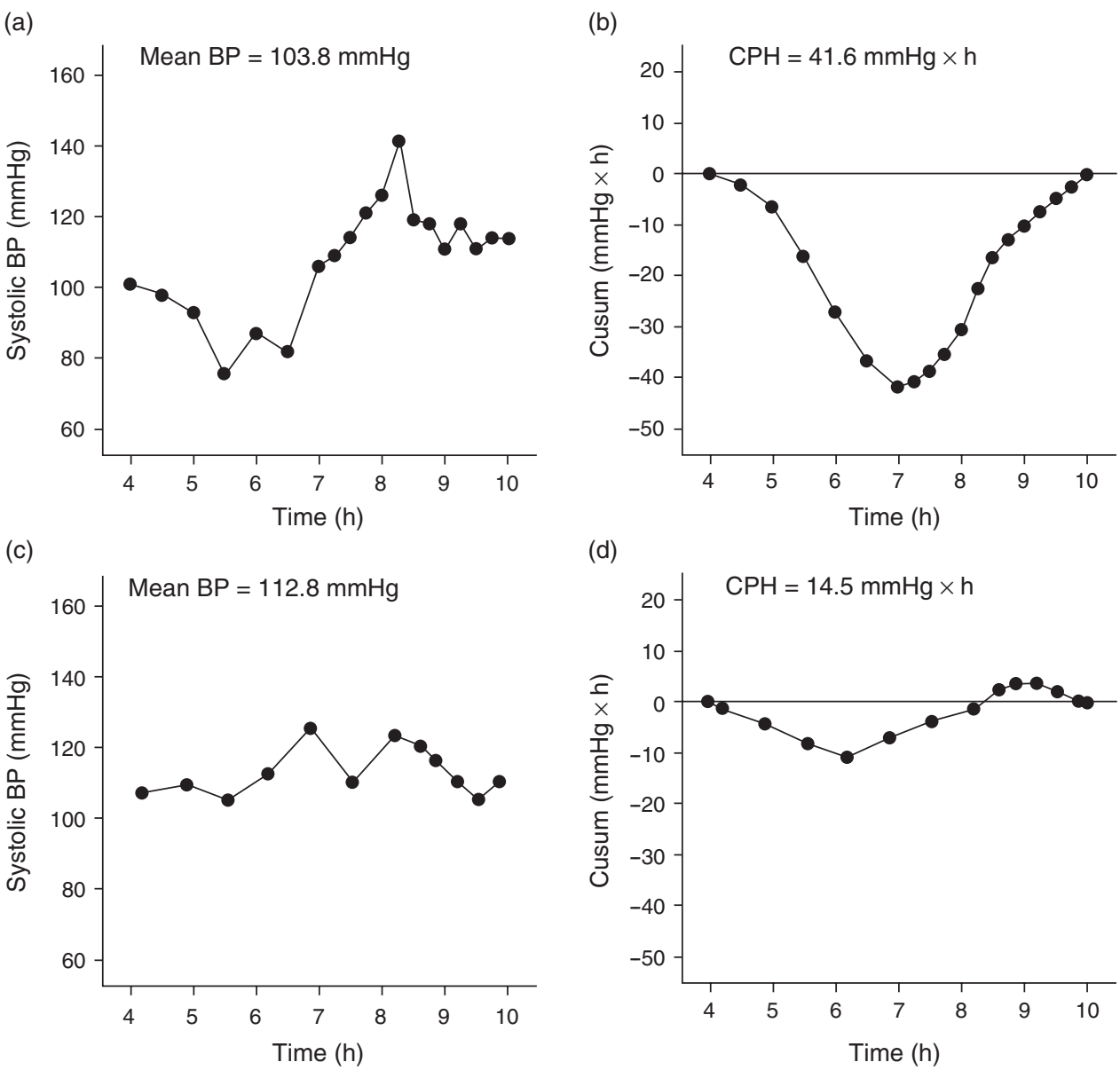

Plots of ambulatory blood pressure (panels a and c), and cusum plot height (b and d) in a patient with ( $a$ and b) and a patient without (c and d) morning surge in systolic blood pressure. $\mathrm{CPH}$, cusum plot height.

surges in $\mathrm{BP}$ or the cusum plot height (Table 1). The repeatability coefficients expressed as percentages of the mean ranged from 14 to $24 \%$ for the BP levels and the night-to-day BP ratios, and from 90 to $272 \%$ for the morning surge in BP and the cusum plot height (Table 1). These estimates, expressed as percentages of the maximal variation ranged from 35 to $56 \%$, and from 51 to $75 \%$, respectively (Table 1 ).

In the categorical analysis of short-term repeatability (Table 3), of 157 patients with available data on the sleep-through morning surge, $89(56.7 \%)$ were consistent nonsurgers, $24(15.3 \%)$ were consistent surgers, and 44 (28.0\%) changed their surging status $(P=0.13$; $\kappa=0.33)$. Of 157 patients with available data on the preawake morning surge, $97(61.8 \%)$ were consistent nonsurgers, $18(8.7 \%)$ were consistent surgers, and $42(26.8 \%)$ changed their status $(P=0.54 ; \kappa=0.28)$. All correlations of differences between repeat recordings in the sleep-through and preawake morning surge, and the cusum plot height with difference in the time of awakening, were nonsignificant $(r<0.14 ; P>0.8)$.

\section{Long-term repeatability on placebo}

In the 219 patients available for the study of the long-term repeatability, the median time-interval between the duplicate measurements was 10 months (interquartile range, 7.7-13.2 months; range, $6-26$ months). The technique of ambulatory $\mathrm{BP}$ recording was consistently oscillometric in 158 patients $(72.2 \%)$ and consistently auscultatory in 42 patients $(19.2 \%)$.

During follow-up, significant decreases occurred in the systolic and diastolic daytime and nighttime BPs $(P<0.05)$, as well as in the preawake morning surge and cusum plot height of systolic pressure (Table 2). The repeatability coefficients expressed as percentages of the mean ranged from 19 to $26 \%$ for the BP levels and the night-to-day $\mathrm{BP}$ ratio, and from 80 to $252 \%$ for the morning surge in $\mathrm{BP}$ and the cusum plot height (Table 2). 

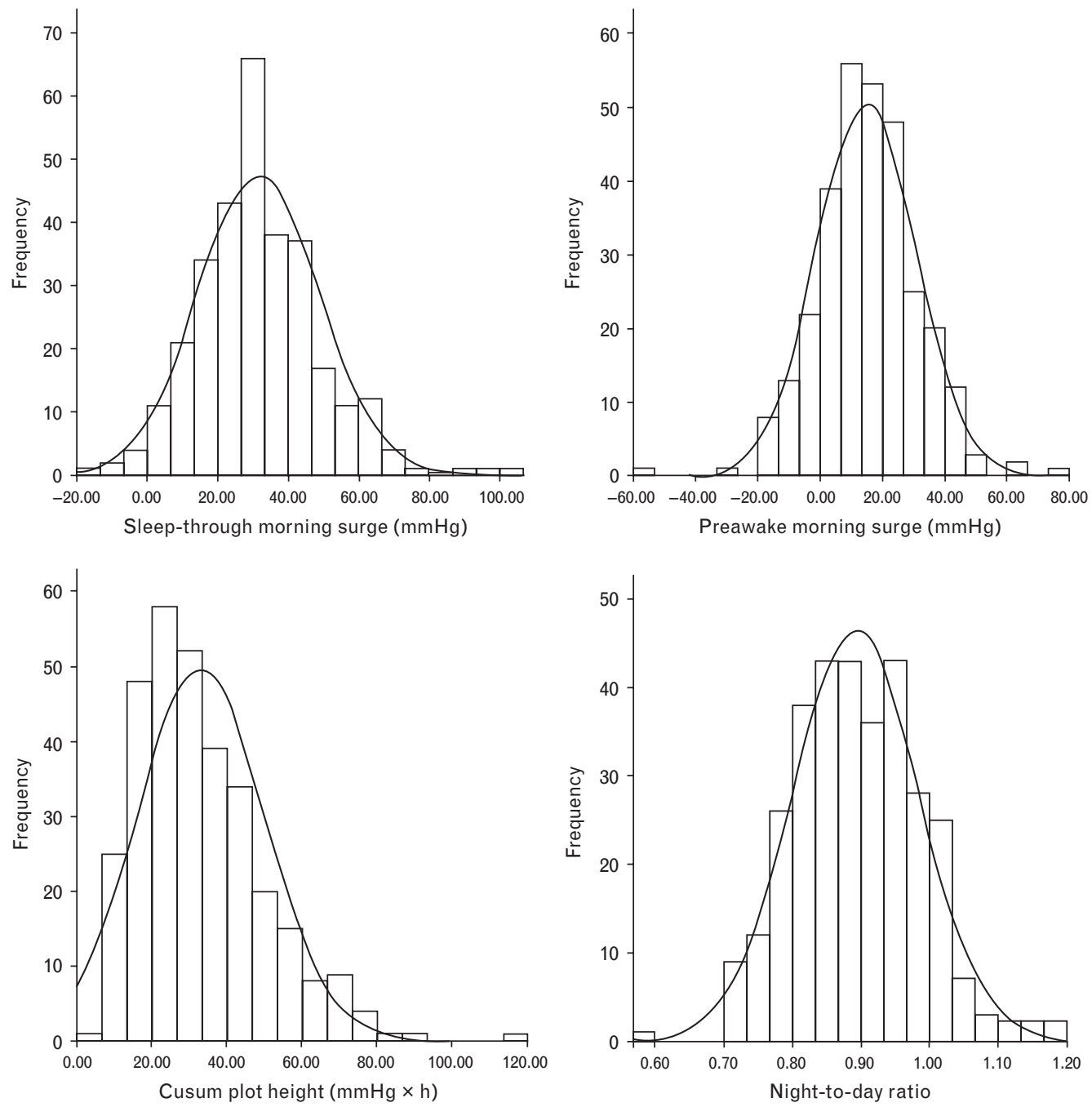

Distributions of the sleep-through and preawake morning surge, the cusum plot height, and night-to-day ratio in 320 patients whose blood pressure was recorded during the run-in placebo period.

These estimates, expressed as percentages of maximal variation, ranged from 45 to $71 \%$ and from 50 to $83 \%$, respectively (Table 2).

In the categorical analysis of long-term repeatability (Table 3), of 206 patients with available data on the sleep-through morning surge, $116(56.3 \%)$ were consistent nonsurgers, $24(11.7 \%)$ were consistent surgers, and 66 $(32.0 \%)$ changed their surging status $(P=0.46 ; \kappa=0.20)$. Of 206 patients with available data on the preawake morning surge, 122 (59.2\%) were consistent nonsurgers, $18(8.7 \%)$ were consistent surgers, and $66(32.0 \%)$ changed their status $(P=0.049 ; \kappa=0.15)$.

\section{Consistency between short-term and long-term repeatability}

Of 62 patients with three recordings of sufficient quality, $28(45.2 \%)$ were consistent nonsurgers, $6(9.7 \%)$ were consistent surgers, and 28 (45.2\%) changed their surging status across the three recordings. The $\kappa$-statistic was 0.25 . The corresponding numbers for a preawake morning surge were $28(45.2 \%), 2(3.2 \%)$, and $32(51.6 \%)$, respectively, with a $\kappa$-statistic of 0.07 .

\section{Discussion}

Several studies have suggested that a rapid rise of BP in the morning might represent an additional risk factor for cardiovascular events in hypertensive patients as well as in the general population $[3,4,6,7,24]$. To our knowledge, only one prior report, however, addressed the reproducibility of the morning surge in BP. To what extent the morning surge is reproducible might be relevant for the interpretation of the aforementioned outcome studies. Indeed high reproducibility might strengthen the prognostic significance of the morning surge. The key finding of our current study was that the BP changes in the 
Table 1 Short-term repeatability of ambulatory blood pressure measurements

\begin{tabular}{|c|c|c|c|c|c|c|c|c|c|}
\hline & \multirow[b]{2}{*}{$N$} & \multirow[b]{2}{*}{ First (mean $\pm \mathrm{SD}$ ) } & \multirow[b]{2}{*}{ Repeat (mean \pm SD) } & \multirow[b]{2}{*}{$P$} & \multicolumn{2}{|c|}{ Difference $^{a}$} & \multicolumn{3}{|c|}{ Repeatability } \\
\hline & & & & & Mean \pm SD & $95 \% \mathrm{Cl}$ & $\mathrm{RC}$ & $\% \mathrm{M}$ & $\% \mathrm{MV}$ \\
\hline \multicolumn{10}{|c|}{ Daytime BP (mmHg) } \\
\hline Systolic & 173 & $158.6 \pm 16.1$ & $157.3 \pm 16.4$ & 0.13 & $-1.3 \pm 10.7$ & -2.9 to 0.4 & 21.5 & 14 & 35 \\
\hline Diastolic & & $85.5 \pm 10.8$ & $84.9 \pm 10.2$ & 0.28 & $-0.7 \pm 8.1$ & -1.9 to 0.6 & 16.2 & 19 & 42 \\
\hline \multicolumn{10}{|c|}{ Nighttime BP (mmHg) } \\
\hline Systolic & 173 & $143.1 \pm 18.3$ & $142.0 \pm 18.5$ & 0.31 & $-1.1 \pm 13.9$ & -3.2 to 1.0 & 27.8 & 20 & 41 \\
\hline Diastolic & & $71.5 \pm 10.6$ & $71.4 \pm 9.9$ & 0.83 & $-0.1 \pm 7.8$ & -1.3 to 1.0 & 15.6 & 22 & 41 \\
\hline \multicolumn{10}{|c|}{ Night-to-day BP ratio } \\
\hline Systolic & 173 & $0.905 \pm 0.10$ & $0.906 \pm 0.10$ & 0.97 & $0.001 \pm 0.09$ & -0.01 to 0.01 & 0.18 & 20 & 50 \\
\hline Diastolic & & $0.840 \pm 0.10$ & $0.845 \pm 0.10$ & 0.54 & $0.005 \pm 0.10$ & -0.01 to 0.02 & 0.20 & 24 & 56 \\
\hline \multicolumn{10}{|c|}{ Sleep-through morning surge (mmHg) [2] } \\
\hline Systolic & 157 & $32.2 \pm 18.1$ & $33.4 \pm 16.9$ & 0.46 & $1.2 \pm 18.7$ & -1.8 to 4.2 & 37.4 & 114 & 63 \\
\hline Diastolic & & $25.2 \pm 12.6$ & $26.1 \pm 12.5$ & 0.32 & $0.8 \pm 11.6$ & -1.0 to 2.6 & 23.2 & 90 & 52 \\
\hline \multicolumn{10}{|c|}{ Preawake morning surge $(\mathrm{mmHg})[2]$} \\
\hline Systolic & 157 & $14.6 \pm 16.8$ & $14.8 \pm 16.6$ & 0.92 & $0.2 \pm 20.0$ & -3.0 to 3.3 & 40.0 & 272 & 75 \\
\hline Diastolic & & $12.3 \pm 11.7$ & $13.0 \pm 12.2$ & 0.51 & $0.6 \pm 12.1$ & -1.3 to 2.6 & 24.2 & 191 & 59 \\
\hline \multicolumn{10}{|c|}{ Cusum plot height $(\mathrm{mmHg} \times \mathrm{h})[19]$} \\
\hline Systolic & 124 & $33.4 \pm 16.9$ & $35.0 \pm 19.8$ & 0.35 & $1.6 \pm 19.4$ & -1.8 to 5.1 & 38.8 & 113 & 62 \\
\hline Diastolic & & $24.8 \pm 13.9$ & $24.0 \pm 13.8$ & 0.50 & $-0.8 \pm 12.6$ & -3.0 to 1.5 & 25.2 & 103 & 51 \\
\hline
\end{tabular}

${ }^{a}$ Difference between repeat minus first recording. The repeatability coefficient (RC) is twice the standard deviation of the signed differences between duplicate measurements, expressed as the percentage of the mean of the repeated recordings $(\% \mathrm{M})$, or as a percentage of four times the standard deviation of the mean value of the two recordings (\%MV). BP, blood pressure; $\mathrm{Cl}$, confidence interval.

morning were poorly reproducible, irrespective of whether they were analysed as a continuous or categorical variable. In the continuous analyses, the repeatability coefficients of the sleep-through and preawake morning surge in $\mathrm{BP}$, and the cusum plot height, were consistently higher than $50 \%$. Higher values of the repeatability coefficient indicate worse reproducibility. For comparison, the repeatability coefficient of the conventionally measured clinic BP is usually around $50 \%$ [25,26]. In the short-term study, the repeatability coefficients for systolic and diastolic daytime and nighttime BPs were approximately $40 \%$. In the categorical analyses of the sleepthrough and preawake morning surge, the $\kappa$-statistics were substantially lower than 0.4 or 0.8 , which are usually considered as thresholds for moderate or high reproducibility, respectively [23]. The $\kappa$-statistics were consistent for both the short-term and long-term repeatability of BP changes in the morning.

Wang et al. [27] studied 36 community-dwelling hypertensive patients, who all were newly diagnosed and had never been treated with BP lowering drugs. These investigators performed ambulatory $\mathrm{BP}$ monitoring each time on a weekday, 1, 5, and 12 weeks after enrolment. They used the correlation coefficients as a measure of agreement. Although they did not find any significant

Table 2 Long-term repeatability of ambulatory blood pressure measurements in the placebo group

\begin{tabular}{|c|c|c|c|c|c|c|c|c|c|}
\hline & \multirow[b]{2}{*}{$N$} & \multirow[b]{2}{*}{ First (mean $\pm \mathrm{SD}$ ) } & \multirow[b]{2}{*}{ Repeat $($ mean $\pm S D)$} & \multirow[b]{2}{*}{$P$} & \multicolumn{2}{|c|}{ Difference $^{\mathrm{a}}$} & \multicolumn{3}{|c|}{ Repeatability } \\
\hline & & & & & Mean \pm SD & $95 \% \mathrm{Cl}$ & $\mathrm{RC}$ & $\% \mathrm{M}$ & $\% \mathrm{MV}$ \\
\hline \multicolumn{10}{|c|}{ Daytime BP (mmHg) } \\
\hline Systolic & 219 & $152.2 \pm 16.0$ & $148.4 \pm 16.8$ & $<0.001$ & $-3.8 \pm 15.6$ & -5.9 to -1.8 & 31.2 & 21 & 54 \\
\hline Diastolic & & $84.2 \pm 10.3$ & $82.2 \pm 9.9$ & $<0.01$ & $-2.0 \pm 9.5$ & -3.3 to -0.7 & 19.0 & 23 & 53 \\
\hline \multicolumn{10}{|c|}{ Nighttime BP (mmHg) } \\
\hline Systolic & 219 & $134.5 \pm 16.6$ & $131.8 \pm 17.7$ & $<0.01$ & $-2.7 \pm 12.6$ & -4.3 to -1.0 & 25.2 & 19 & 64 \\
\hline Diastolic & & $70.2 \pm 9.6$ & $69.0 \pm 10.0$ & 0.03 & $-1.2 \pm 8.1$ & -2.3 to -0.2 & 16.2 & 23 & 45 \\
\hline \multicolumn{10}{|c|}{ Night-to-day BP ratio } \\
\hline Systolic & 219 & $0.885 \pm 0.09$ & $0.890 \pm 0.10$ & 0.43 & $0.005 \pm 0.10$ & -0.01 to 0.02 & 0.20 & 22 & 71 \\
\hline Diastolic & & $0.837 \pm 0.09$ & $0.843 \pm 0.11$ & 0.34 & $0.006 \pm 0.11$ & -0.01 to 0.02 & 0.22 & 26 & 69 \\
\hline \multicolumn{10}{|c|}{ Sleep-through morning surge (mmHg) [2] } \\
\hline Systolic & 206 & $31.6 \pm 17.0$ & $30.2 \pm 15.4$ & 0.30 & $-1.4 \pm 19.6$ & -4.1 to 1.3 & 39.2 & 127 & 76 \\
\hline Diastolic & & $23.9 \pm 11.2$ & $24.6 \pm 12.0$ & 0.49 & $0.7 \pm 14.3$ & -1.3 to 2.6 & 28.6 & 118 & 78 \\
\hline \multicolumn{10}{|c|}{ Preawake morning surge $(\mathrm{mmHg})[2]$} \\
\hline Systolic & 206 & $15.8 \pm 15.3$ & $12.4 \pm 14.3$ & 0.01 & $-3.4 \pm 18.4$ & -5.9 to -0.9 & 36.8 & 261 & 79 \\
\hline Diastolic & & $11.2 \pm 11.0$ & $11.2 \pm 11.1$ & 0.98 & $0.02 \pm 14.1$ & -1.9 to 2.0 & 28.2 & 252 & 83 \\
\hline \multicolumn{10}{|c|}{ Cusum plot height $(\mathrm{mmHg} \times \mathrm{h})[19]$} \\
\hline Systolic & 126 & $34.0 \pm 15.5$ & $30.7 \pm 15.5$ & 0.03 & $-3.3 \pm 16.8$ & -6.3 to -0.3 & 26.0 & 80 & 50 \\
\hline Diastolic & & $23.7 \pm 11.7$ & $21.9 \pm 10.5$ & 0.14 & $-1.8 \pm 13.6$ & -4.2 to 0.6 & 27.2 & 119 & 78 \\
\hline
\end{tabular}

${ }^{\text {a }}$ Difference between repeat minus first recording. The repeatability coefficient (RC) is twice the standard deviation of the signed differences between duplicate measurements; expressed as the percentage of the mean of the repeated recordings $(\% \mathrm{M})$, or as a percentage of four times the standard deviation of the mean value of the two recordings (\%MV). BP, blood pressure; Cl, confidence interval. 
Table 3 Categorical analysis of short-term and long-term reproducibility of the morning surge

\begin{tabular}{|c|c|c|c|c|c|}
\hline & First & Second vs. first $(n=157)$ & ${ }^{*} P, \kappa$ & Third vs. first $(n=206)$ & ${ }^{*} P, \kappa$ \\
\hline Sleep-through MS [2] $]^{\ddagger}$ & $\begin{array}{l}<40 \mathrm{mmHg} \\
\geq 40 \mathrm{mmHg}\end{array}$ & $\begin{array}{l}<40 \mathrm{mmHg} \text { vs. } \geq 40 \mathrm{mmHg} \\
89(56.7 \%) \text { vs. } 27(17.2 \%) \\
17(10.8 \%) \text { vs. } 24(15.3 \%)\end{array}$ & $P=0.13, \kappa=0.33$ & $\begin{array}{l}<40 \mathrm{mmHg} \text { vs. } \geq 40 \mathrm{mmHg} \\
116(56.3 \%) \text { vs. } 30(14.5 \%) \\
36(17.5 \%) \text { vs. } 24(11.6 \%)\end{array}$ & $P=0.46, \kappa=0.20$ \\
\hline Preawake MS [2] $]^{\ddagger}$ & $\begin{array}{l}<25 \mathrm{mmHg} \\
\geq 25 \mathrm{mmHg}\end{array}$ & $\begin{array}{l}<25 \mathrm{mmHg} \text { vs. } \geq 25 \mathrm{mmHg} \\
97(61.8 \%) \text { vs. } 19(12.1 \%) \\
23(14.6 \%) \text { vs. } 18(11.5 \%)\end{array}$ & $P=0.54, \kappa=0.28$ & $\begin{array}{l}<25 \mathrm{mmHg} \text { vs. } \geq 25 \mathrm{mmHg} \\
122(59.2 \%) \text { vs. } 25(12.1 \%) \\
41(19.9 \%) \text { vs. } 18(8.7 \%)\end{array}$ & $P=0.049^{*}, \kappa=0.15$ \\
\hline
\end{tabular}

Second vs. first refers to repeat blood pressure ambulatory recordings in 157 patients during the placebo run-in period at the median interval 33 days or third vs. first refers to the ambulatory blood pressure recording during follow-up minus the first recording during placebo run-in period, obtained in 206 patients at a median interval of 10 months. MS, morning surge. ${ }^{*} P$-value of McNemar's test.

differences in the sleep-through morning surge between the three recordings, the correlation coefficients between the first and the second, the second and the third, and the first and the third recording were only $0.41,0.48$, and 0.57 , respectively. Zakopoulos et al. [28] studied 20 patients with mild to moderate essential hypertension, who underwent four repeated ambulatory recordings, each time on the same day of the week, at 30-day intervals. Antihypertensive therapy was discontinued for 2 weeks before each recording. These investigators reported that the hourly BP means from 04:00 to 10:00 h were similar in the four consecutive recordings for systolic as well diastolic BP. Nevertheless, we found Zakopoulos' study difficult to interpret, because it was underpowered, and because it did not include any specific reproducibility statistics.

Several investigators demonstrated an inverse association or a negative correlation between the morning surge in BP and the level of the nighttime BP [2,7,27]. Subjects with the lowest nighttime BP usually experienced the largest increase in BP on awakening. Dippers and extreme dippers were overrepresented among the morning surgers [2]. In fact, we confirmed these findings in our current study (data not shown). We believe that the inverse association between the morning surge in $\mathrm{BP}$ and the nighttime BP level is a mathematical artefact. Indeed, the relation between the difference between two measurements, such as the morning and nighttime $\mathrm{BP}$ and one of the components of this difference, for instance the morning BP, must be statistically significant [29]. Moreover, from a biological point of view, the rise in $\mathrm{BP}$ in the morning must be larger in subjects with a low nighttime BP (dippers) as compared to those, whose BP level at night is elevated (nondipper).

O'Brien et al. [30] introduced plotting of cumulative sums as a simple statistical technique to analyse trends over time in ambulatory BP recordings. Stanton et al. [19] described the method in detail. The height of the cusum plot, which reflects the extent and duration of alterations of $\mathrm{BP}$ over time, is a measure for the circadian $\mathrm{BP}$ changes in 24-h BP recordings. Stanton found in 22 hypertensive patients with duplicate recordings at a 4 -week interval that the repeatability coefficients of systolic and diastolic cusum plot height were 68 and $61 \%$, respectively. Stanton et al. [19] and Burn et al. [31] hypothesized that the cusums method, which is independent of fixed time periods, would improve precision and reproducibility. In line with this hypothesis [19,31] and the 2003 recommendations of the European Society of Hypertension [32], we applied the cusums approach to a time-window spanning $6 \mathrm{~h}$, including the period of awakening. Our estimates of repeatability were similar to those reported by Stanton for whole-day recordings [19].

The present study must be interpreted within the context of its potential limitations and strengths. We only studied older patients with isolated systolic hypertension. First, our findings might not be generalizable to younger subjects or to the population at large. Second, we did not monitor physical activity by actigraphy and could therefore not adjust for this potential confounder. Finally, investigators used various types of devices to record the ambulatory BP. Nevertheless, our estimate of the repeatability of the cusum plot height was in concordance with Stanton's findings [19]. All recordings in her study [19] were obtained with oscillometric SpaceLabs 90202 recorders. On the contrary, only one previous study [27] reported on the reproducibility of sleep-through morning surge, over intervals ranging from 4 weeks to 3 months. Our short-term and long-term repeatability study included 173 and 219 patients, respectively. We applied established statistical method to study repeatability, and as recommended by Bland and Altman [20,29] we avoided correlation coefficients as measure of agreement.

In conclusion, the morning surge in $\mathrm{BP}$ is poorly reproducible, even at a median interval of only 1 month, irrespective of whether the BP changes during the morning surge are analysed as continuous or categorical variables. Poor reproducibility, however, does not preclude that a statistical parameter derived from ambulatory BP recordings can have prognostic significance, as shown in previous papers on the morning surge in BP [2,6,7,24]. Indeed, Japanese researchers showed that morning surge in $\mathrm{BP}$, in spite of poor reproducibility, added to the stratification of risk both in hypertensive patients [2,6] and the population at large [7,24]. Further research should clarify to what extent, on a continuous scale, the morning surge in $\mathrm{BP}$ is a predictor of outcome over 
and beyond classical cardiovascular risk factors and the 24-h BP.

\section{Acknowledgements}

The European Union (grants IC15-CT98-0329-EPOGH, LSHM-CT-2006-037093, and HEALTH-2007-201550); the Fonds voor Wetenschappelijk Onderzoek Vlaanderen, Ministry of the Flemish Community, Brussels, Belgium (grants G.0424.03 and G.0575.06); and the Katholieke Universiteit Leuven, Belgium (grants OT/99/28, OT/00/ 25 and OT/05/49) gave support to the Studies Coordinating Centre. J.A.S. is holder of the Pfizer Chair for Hypertension and Cardiovascular Research. The bilateral scientific and technological collaboration between Poland and Flanders, Ministry of the Flemish Community, Brussels (grant BIL/05/22) supported the fellowship of Barbara Wizner in Leuven. The Dutch Heart Foundation (Dr E. Dekker grant), Den Haag, The Netherlands, supported the fellowship of D.G. Dechering. A list of the Syst-Eur investigators involved in the substudy on ambulatory blood pressure monitoring is available in reference [26]. The authors gratefully acknowledge the expert assistance of Sandra Covens and Ya Zhu (Studies Coordinating Office, Leuven, Belgium).

There are no conflicts of interest.

\section{References}

1 Cohen MC, Rohtla KM, Lavery CE, Muller JE, Mittleman MA. Meta-analysis of the morning excess of acute myocardial infarction and sudden death. Circulation 1997; 79:1512-1515.

2 Kario K, Pickering TG, Umeda Y, Hoshide S, Hoshide Y, Morinari M, et al. Morning surge in blood pressure as predictor of silent and clinical cerebrovascular disease in elderly hypertensives. A prospective study. Circulation 2003; 107:1401-1406.

3 Gosse P, Lasserre R, Minifie C, Lemetayer P, Clementy J. Blood pressure surge on rising. J Hypertens 2004; 22:1113-1118.

4 Kaneda R, Kario K, Hoshide S, Umeda Y, Hoshide Y, Shimada K. Morning blood pressure hyper-reactivity is an independent predictor for hypertensive cardiac hypertrophy in a community-dwelling population. Am J Hypertens 2005; 18:1528-1533.

5 Kario K. Vascular damage in exaggerated morning surge in blood pressure. Hypertension 2007; 49:771-772.

6 Kario K, Ishikawa J, Pickering TG, Hoshide S, Eguchi K, Morinari M, et al. Morning hypertension: the strongest independent risk factor for stroke in elderly hypertensive patients. Hypertens Res 2006; 29:581587.

7 Metoki H, Ohkubo T, Asayama K, Obara T, Hashimoto J, Totsune K, et al. Prognostic significance for stroke of a morning pressor surge and a nocturnal blood pressure decline: the Ohasama Study. Hypertension 2006; 47:149-154.

8 Mochizuki Y, Okutani M, Donfeng Y, Iwasaki H, Takusagawa M, Kohno I, et al. Limited reproducibility of circadian variation in blood pressure dippers and nondippers. Am J Hypertens 1998; 11:403-409.

9 Omboni S, Parati G, Palatini P, Vanasia A, Muiesan ML, Cuspidi C, et al. Reproducibility and clinical value of nocturnal hypotension: prospective evidence from the SAMPLE study. J Hypertens 1998; 16:733-738.

10 Cuspidi C, Meani S, Salerno M, Valerio C, Fusi V, Severgnini B, et al. Reproducibility of nocturnal blood pressure fall in early phases of untreated essential hypertension: a prospective observational study. J Hum Hypertens 2004; 18:503-509.

11 Cuspidi C, Meani S, Sala C, Valerio C, Fusi V, Zanchetti A, et al. How reliable is isolated clinical hypertension defined by a single 24-h ambulatory blood pressure monitoring? Journal of Hypertension 2007; 25:315-320.
12 Rey RH, Martin-Baranera M, Sobrino J, Gorostidi M, Vinyoles E, Sierra C, et al. Reproducibility of the circadian blood pressure pattern in 24-h versus 48-h recordings: the Spanish Ambulatory Blood Pressure Monitoring Registry. J Hypertens 2007; 25:2406-2412.

13 Birkenhager A, van den Meiracker A. Causes and consequences of a nondipping blood pressure profile. Neth J Med 2007; 65:127-131.

14 Staessen J, Amery A, Clement D, Cox J, De Cort P, Fagard R, et al. Twenty-four hour blood pressure monitoring in the Syst-Eur trial. Aging Clin Exp Res 1992; 4:85-91.

15 Staessen JA, O'Brien ET, Thijs L, Fagard RH. Modern approaches to blood pressure measurement. Occup Environ Med 2000; 57:510-520.

16 O'Brien E, Asmar R, Beilin L, Imai Y, Mancia G, Mengden T, et al. Practice guidelines of the European Society of Hypertension for clinic, ambulatory and self blood pressure measurement. $J$ Hypertens 2005; 23:697-701.

17 Franklin SS, Larson MG, Khan SA, Wong ND, Leip EP, Kannel WB, et al. Does the relation of blood pressure to coronary heart disease change with aging? The Framingham Heart Study. Circulation 2001; 103:12451249.

18 Boggia J, Li Y, Thijs L, Hansen TW, Kikuya M, Björklund-Bodegírd K, et al. Prognostic accuracy of day versus night ambulatory blood pressure: a cohort study. Lancet 2007; 370:1219-1229.

19 Stanton A, Cox J, Atkins N, O'Malley K, O'Brien E. Cumulative sums in quantifying circadian blood pressure patterns. Hypertension 1992; 19:93-101.

20 Bland JM, Altman DG. Statistical methods for assessing agreement between two methods of clinical measurement. Lancet 1986; 2:307310.

21 Dewitte K, Fierens C, Stockl D, Thienpont LM. Application of the Bland-Altman plot for interpretation of method-comparison studies: a critical investigation of its practice. Clin Chem 2002; 48:799-801.

22 Staessen J, Bulpitt CJ, O'Brien E, Cox J, Fagard R, Stanton A, et al. The diurnal blood pressure profile. A population study. Am J Hypertens 1992; 5:386-392.

23 Altman DG. Practical statistics for medical research. New York: Chapman and Hall; 1991.

24 Metoki H, Ohkubo T, Kikuya M, Asayama K, Obara T, Hara A, et al. Prognostic significance of night-time, early morning, and daytime blood pressures on the risk of cerebrovascular and cardiovascular mortality: the Ohasama Study. J Hypertens 2006; 24:1841-1848.

25 Thijs L, Celis H, Clement D, Gil-Extremera B, Kawecka-Jaszcz K, Mancia G, et al. Conventional and ambulatory blood pressure measurement in older patients with isolated systolic hypertension: second progress report on the ambulatory blood pressure monitoring project in the Syst-Eur trial. Blood Press Monit 1996; 1:95-103.

26 Emelianov D, Thijs L, Staessen JA, Celis H, Clement D, Davidson C, et al. Conventional and ambulatory blood pressure measurement in older patients with isolated systolic hypertension: baseline observations in the Syst-Eur trial. Blood Press Monit 1998; 3:173-180.

27 Wang MY, Huang CJ, Chang NC, Tsai PS. Reproducibility of morning blood pressure surge and its relation to blood pressure reactivity. Clin Exp Hypertens 2007; 29:357-368.

28 Zakopoulos NA, Nanas SN, Lekakis JP, Vemmos KN, Kotsis VT, Pitiriga VC, et al. Reproducibility of ambulatory blood pressure measurements in essential hypertension. Blood Press Monit 2001; 6:41-45.

29 Bland JM, Altman DG. Comparing methods of measurement: why plotting difference against standard method is misleading. Lancet 1995; 346:1085-1087.

30 O'Brien E, Perry I, Sheridan J, Atkins N, O'Malley K. Application of cusums to ambulatory blood pressure data: a simple statistical technique for detecting trends over time. J Hypertens 1989; 7:707-709.

31 Burn J, Sims AJ, Ford GA, Murray A. Factors affecting the use of cumulative sums in the analysis of circadian blood pressure. Physiol Meas 2006; 27:529-538.

32 O'Brien E, Asmar R, Beilin L, Imai Y, Mallion JM, Mancia G, et al. European Society of Hypertension recommendations for conventional, ambulatory and home blood pressure measurement. J Hypertens 2003; 21:821-848. 